\title{
A multi-scale, morphological interpretation of the sustainable city
}

\author{
N. Long, F. Rousseaux \& D. Vye \\ UMR LIENSS - Université de La Rochelle, France
}

\begin{abstract}
This article seeks to highlight a shift in development of the city towards a sustainable model through the prism of morphology. It presents multi-scale, morphological keys for understanding, making it possible to identify and detail the physical and structural elements which comprise the sustainable city. Via these keys for understanding, the article endeavours to identify the various physical elements and structures of this urban landscape which is undergoing radical transformation. On what scale is the drive towards a sustainable city the most noteworthy? Does the slogan "act locally, think globally" also apply to the urban territory? This paper begins by outlining the concepts of the sustainable city. There then follows a description and analysis of morphological keys for understanding the sustainable city. Finally, the concluding part covers application of these keys to the city of Nantes, which hosts several sustainable development projects and will assume the mantle of European Green Capital in 2013.
\end{abstract}

Keywords: urban morphology, sustainable city, Nantes, multi-scale.

\section{Introduction}

The concept of the "sustainable city" is often defined with reference to the three pillars of sustainable development, sometimes placing a greater emphasis on the environmental component due to the significant impact of the city on the natural ecosystem [1]. As societies have evolved, urbanisation has become inevitable and today over half of the world's population live in urban areas and should double to reach $70 \%$ of the world's population in 2050 [2].

For decades, an ideological current extolling ecology in the urban environment has become increasingly forceful to rebuild cities in balance with 
nature [3]. In this context, the city development is fraught with consequences because of the city is the principal sources of GGEs (transport, industry, etc.) and consumes a significant quantity of energy which is almost entirely imported and produces waste [4]. However, cities try to answer to environmental changes through local initiatives, in particular in Europe where cities are become real laboratories of ecological innovations [5]. The cities which are signatories to the Aalborg Charter $(620$ local authorities which ratified the "Aalborg Commitments" in 2009), undertake to implement policies to make their city sustainable [6].

Thus, for twenty or so years, new developments are emerging, eco-districts are springing to life offering an "original" urban landscape. In terms of the territory, specifications with a significant impact on urban forms are proposed: the compact city and functional 'mixity' are principles which are fostered and which have visible consequences for development. In general terms, a new urban morphology is taking shape. It is remarkable on several scales [7].

Urban morphology can be defined, on the large scale, by the very morphology of buildings, how they are laid out in the space and land cover. On a medium and small scale, urban morphology more specifically concerns analysis of the city's forms and structures [7-9]. Urban morphology has elucidated the history of urban planning for around thirty years. Analysis of urban morphology as we define it in this article corresponds to the analysis of "everything which can be seen". This approach excludes analysis of urban planning documents or statistical or sociological surveys. Is it sufficient? No doubt it is not but it is necessary and indicative: urban morphology remains intrinsically tied to social behaviour and political decisions. It is the visible consequence of the development decisions of a territory or district. Finally, it is a marker of the dominant, successive benchmarks in the history of urban planning, from the city which was hygiene-focused and then functional before becoming sustainable since the 1990s.

The question raised in this article concerns the morphological interpretation via the physical and structural elements which make up the sustainable city, whose definitions and principles will be described in an initial part. This exclusively morphological interpretation is based on a multi-scale approach : in a second part we present keys for understanding which list the morphological elements characterising the sustainable city via the definition assigned to it. Application of the keys for understanding will be made in a final point and will concern the city of Nantes, which hosts numerous sustainable development projects.

\section{Identifying the sustainable city}

The sustainable city is often defined as a dense city, the city of short distances, of the struggle against urban sprawl, which ensures social mixity and functional diversity, respects ecosystems and natural, cultural and heritage-related resources $[10,11]$. It develops as a priority in relation with public transport networks, which have been unable to follow such a spatial development of the city. 
Similarly, environmental inequalities generated by the city are targeted by Cyria Emelianoff's definition [12]:

- a city capable of maintaining itself over time, retaining an identity, a collective meaning, a long-term dynamism,

- a city which offers quality of life in all locations and less pronounced differentials between living environments, requiring high social and functional mixity,

- a city which gives birth to political and collective projects along the lines of the Agenda 21 of Rio,

- a city which must not export the costs of urbanisation and its development to other and future populations, future generations and other ecosystems.

This latter point describing the sustainable city can be associated with the concept of the self-sufficient city [13]. It should thus be capable of ensuring the local satisfaction of essential needs which are fundamental to its functioning. The city also manages what it produces: development of local agriculture with short circuits, use of renewable energy produced locally, avoiding the importation of fossil energy and, finally, management of its waste [14].

Today, the most concrete and visible results can also be seen through the emergence of a new approach to urbanisation. This is giving rise to original urban landscapes, produced during the creation of eco-districts or operations to renovate and redevelop buildings, but also by turning to account non-man-made space henceforth associated with the territories of the sustainable city such as urban forests. These are urban forms which we will endeavour to identify, on different scales, via three major criteria of sustainability, namely, mixity, quality of life and cost management, since the morphological approach does not enable us to analyse the initial criterion described by Emelianoff.

\section{Proposal of multi-scale keys for understanding urban sustainability via its morphology}

In the context of our examination of urban sustainability, morphology can reflect organisation of the space of varying rationality and its optimisation in relation to resources. It is also a reason for the changing behaviour of residents.

We propose keys for understanding the sustainable city which are comprised of urban morphology elements. How does sustainability translate into morphology? However, the idea is to analyse the form of the city via the prism of the definition of the sustainable city and not to judge its supposed "sustainability". The sustainable city is analysed as an object, a structure which is characterised by its forms. These elements concern three forms of sustainability borrowed from definitions of the sustainable city: mixity, quality of life and cost management.

The question of mixity can correspond to buildings, functions or forms of land use (natural spaces, farming spaces, built-up spaces). Although diversity characterises urbanity, the question of mixity goes further and envisages positive 
interactions, complementaries between several elements of diversity: for example, the mixity of functions within part of the urban space, like the presence of job- and service-creating activities, makes it possible to favour the city of short distances by limiting journeys and can help improve the well-being of inhabitants. Even if the question of social inequalities cannot be immediately identified in our study favouring the morphological approach, it is a necessary backdrop to our consideration of sustainability.

The quality of life raises the question of nature's place in the city, according to the premise that this helps enhance the well-being of resident populations: calming effect, possible link with lower crime $[15,16]$. It will then be a question of determining the types of nature present in the urban fabric: parks, public gardens, green corridors, etc.

As for the question of cost management (whether ecological, economic or social) generated by the city, it is generally the compact city which is set up as a model of sustainability even if this is open to debate $[17,18]$. It may then be a question of evaluating the extent to which the forms of urbanisation related to residential spaces or zones of industrial, commercial and small tradesmen activities optimise the (natural, territorial) resources in which the city plays its part and develops.

These three entry points relating to the sustainable city can be identifiable on several scales. Indeed, numerous authors have endeavoured to analyse urban morphology through the prism of sustainability either in terms of the supra-urban territory, or on an infra-urban scale such as the district or even in terms of the building $[19,20]$.

We will therefore individualise four levels of scale, each of which makes it possible to identify the challenges of different sustainability [7].

- the building which by its degree of dilapidation, type of construction material, form or exposure, the presence of otherwise of plant life, can also indicate its degree of sustainability;

- the district, because it also represents a highly relevant scale for analysis of the territory experienced (for eco-districts examples, Vauban Freiburg, BedZed - London) and because it makes it possible to identify whether nor not eco-districts are present within the city;

- the city, in the morphological sense of urban expansion, in other words, the city marked by uninterrupted built-up areas, the question of the structure and the density of the buildings for instance, of land use, the presence of green and blue grids which bear witness to the "naturalness" of the city and the willingness to reinforce biodiversity in the city;

- the supra-urban territory, in other words, the city "beyond the walls" including its area of direct influence and comprising, in particular, the outlying semi-urban areas as well as interstitial farming or natural spaces. This scale makes it possible to demonstrate the key challenge of urban sprawl related to housing or industrial estates; that of the consumption of farming resources or the presence of recreational areas related to nature (urban forests, green belts). 


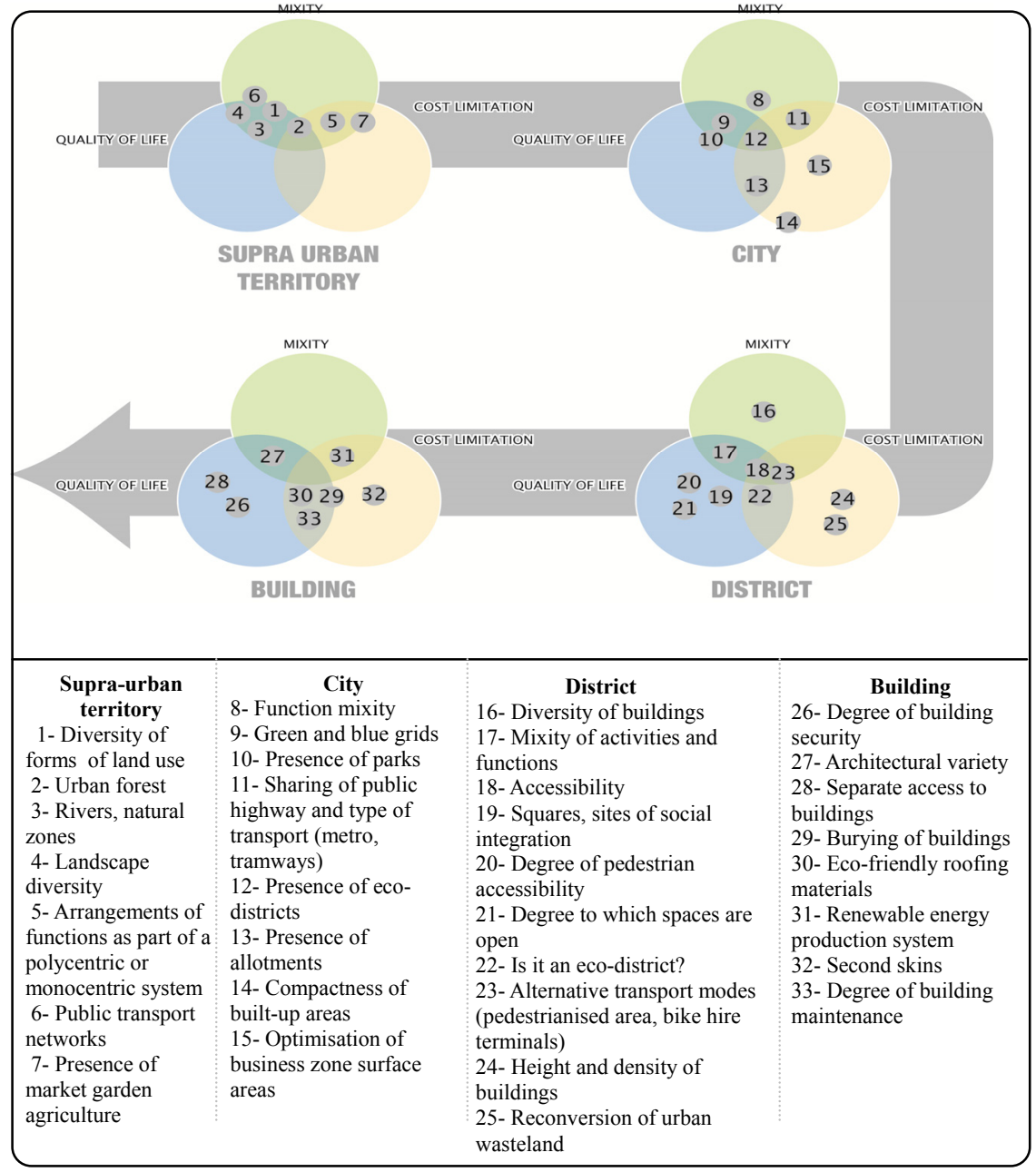

Figure 1: Morphological criteria and elements of city sustainability on four scales.

Figure 1 presents all of these elements and intersects the scales of analysis and sustainability criteria. Each of the 33 elements is shown according to its belonging to the related scales and/or to three entry points into sustainability. The diagram also highlights how these three entry points are cross-cutting, the latter corresponding to three overlapping circles. For example, criterion 3 (presence of rivers or natural areas), identifiable on the scale of the supra-urban territory, is both an element relating to quality of life and to mixity (landscape, functional).

This grid can be applied to Nantes, an attractive metropolis in Western France. Renowned for its quality of life, the Nantes Metropolis has, since the 
mid 1980s, stood out for public policies undertaken by local players aimed at embracing the ideal of the sustainable city.

\section{Application on the territory of the Nantes Metropolis}

Applying these keys for understanding to these different spatial scales means a choice needs to be made as to which territory they may correspond. This choice of a territory, defined more at a political than geographical level, is open to debate but meets a need for cross-referencing with available data for analysis, generally provided at an administrative scale. According to the definitions offered in the preceding paragraph, it can be supposed that the supra-urban territory corresponds to the territory of the Nantes Metropolis. Indeed, it encompasses the urban expansion of the metropolis, fairly outlying towns breaking away from the urban expansion and, for much of the surface area, farming land and natural spaces. However, this choice can be restrictive to represent the zone of influence or the actual population centre of Nantes. However, it is difficult for the scale of the city to be limited to the municipal area of Nantes given that the uninterrupted housing, commonly known as urban expansion, extends to several towns (figure 2). The scale of the city can correspond in this case to urban expansion. In our case, the scale of the district will correspond to a portion of the urban fabric, in other words, either a spatial entity defined in the political and administrative sense as a ZAC (integrated development zone) or a geographical entity (island).

These choices of territorial scales enable us to come up with a database and information and knowledge sources corresponding to each of the indicators proposed. It is firstly all about testing the feasibility of such keys of understanding by applying them to a concrete case but also assessing the tools, the sources available for such a project.

Nantes Metropolis encompasses rivers, forests and agriculture (figure 2). This diverse landscape contributes to the diversity of the territory's land covers. Wine-growing areas occupy the south of the Loire, livestock farming is primarily to be found in the west and north and market gardening in the east. This territory is therefore marked to a high degree by a varied agricultural identity (see map [21]). The river helps to structure the space.

With the Loire now placed centre stage, it is an asset to be presented to best effect as a line of communication and site for leisure outings. Its tributary, the Erdre, also plays an important role as an intersection between the city and the country by means of its upgraded banks.

In order to preserve its natural spaces and agriculture, the Nantes Metropolis has clearly committed, in terms of its urban project, to limiting urban sprawl, protecting farming and reducing use of private vehicles. This is primarily a question of organising mobility within this territory. The Nantes Metropolis has just opened its first tram-train line and a second line is planned in 2012. The presence of 38 park-and-ride points on the edge of Nantes offers semi-urban populations an alternative to driving their cars in the city. The transport mode and urban sprawl are closely linked: urban sprawl continues in some towns in the 


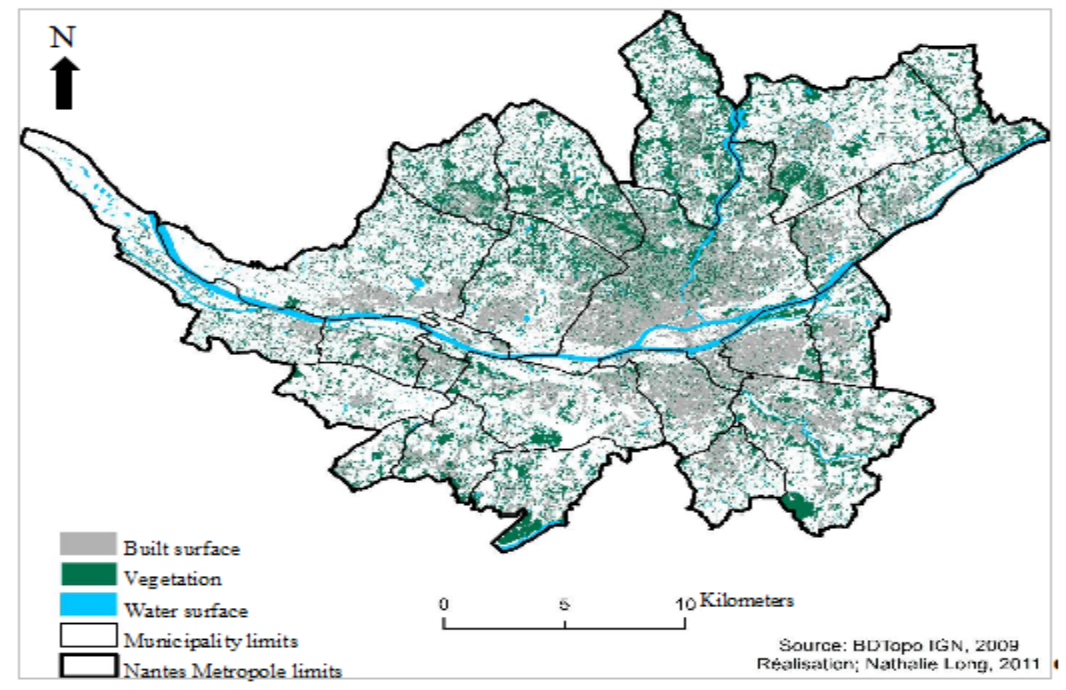

Figure 2: $\quad$ Land use in the Nantes Metropolises.

inner suburbs such as Saint-Herblain and Carquefou. Between 1999 and 2004, they have seen their urbanised surface area rise by $8 \%$ to $10 \%$, according to data in the "Land used methods" database produced by the Conseil Général de LoireAtlantique [22]. These are primarily residential zones with a smattering of parks and urban gardens. However, these extensions remain localised and are juxtaposed with existing urban spaces. In all, they represent less than $14 \mathrm{~km}^{2}$ so mixity seems extremely limited.

The result of this urban planning should enable greater preservation of local agriculture. Local redistribution of agricultural produce is favoured by the creation of farmers' markets or AMAPs (associations for the maintenance of local farming). There are more than forty in the department and around ten production sites on the territory of the Nantes Metropolis [23]. These direct sales favour short circuits and foster semi-urban eco-friendly agriculture.

Natural spaces are also protected or even regenerated by the introduction of urban forests. "The European Green Capital" event in 2013 has, for a number of years, heralded the preservation and the development of three urban forests on the territory to eventually cover around 1400 ha by 2030. The aim is to consolidate and develop links between existing forests and green corridors in the city.

Like the supra-urban territory, the city of Nantes benefits from natural spaces, artificial green spaces and water zones, highly present and naturally woven into the urban fabric. The green and blue corridors represented by four rivers, drive through the urban fabric to the heart of the city. These leafy waterways are ideal for walking and cycling, enjoying nature, catching a breath of fresh air in the city. The Loire crosses the city from east to west and is showcased by the renovation and refurbishment of the Ile de Nantes. Urban green spaces such as parks take up significant surface area, such as the Parc du Grand Blottereau 
(37ha) or the Jardin des Plantes (7ha) in the city centre. From horticultural parks to "wilderness" parks, Nantes has for several years opted for differentiated management of its green spaces, offering a diverse landscape within the city boundaries.

As for all major metropolises, commercial and industrial activities have been pushed to the city outskirts, like the Atlantis shopping centre, the second biggest in the region, to the west of the city. However, there is a clear will to enhance or even develop smaller shopping centres such as the Beaulieu complex on the Ile de Nantes which has been renovated and recently extended to improve access and its integration into the urban fabric. In particular, it benefits from the creation of the "busway" line with a dedicated bus lane, connecting the city's southern gateway with the city centre and brought into service in late 2006.

In fact, Nantes developed its public transport offering very early on. The tramway was one of the first to come into service in France after World War Two and the network is the third largest in the country. Installation of this ecofriendly transport mode in the urban fabric is also aimed at preserving the balance between artificial and planted surface areas thanks to grass-covered tracks (line 1). The presence of park-and-drive points also favours use of this transport mode. In addition, "soft" transport modes are promoted $(368 \mathrm{~km}$ network of cycle paths). Finally, making the most of natural resources, a "navibus" network has been set up on the Erdre, making it possible to run services between both banks. By these means, Nantes is endeavouring to limit the environmental impact of its development.

In terms of urban planning, three development projects concerning ecodistricts have been trailed: Saint-Joseph-de-Porterie, La Bottière-Chénaie and La Prairie aux Ducs. They are in progress with the latter two having received the ministerial eco-district label. These urban development operations may only be dotted around the urban fabric but they set the city on course for more ecofriendly development. However, the city is growing denser, sometimes to the detriment of townhouses with gardens which are making way for 5- to 10-storey buildings, taking up the entire plot. The urban fabric is being renewed.

In fact, at the district level, Nantes offers two examples of different sustainable developments: one concerns an operation to renovate/ redevelop: Ile de Nantes and the second concerns a construction on wasteland : La BottièreChénaie. For the last one, it is worth noting the diversity of building types in terms of the shape, height and materials, with collective style buildings in horizontal blocks and forms which evoke medinas with bright colours and intermediate type housing, in other words, collective but with separate entrances for each housing unit. These buildings are grouped together into a block offering a certain density of housing and leaving extensive surface areas free to accommodate a park, reservoirs for collecting rain water and allotments.

The mixity of functions also enjoys a strong presence. This district includes housing, local shops, a school and a media library (figure 3 ). In terms of its accessibility, it lies close to the tramway and is on bus routes. Cycle paths and a pedestrian space have been developed to favour "soft" transport modes to meet daily needs but also to create zones where people can interact. Here we can note 

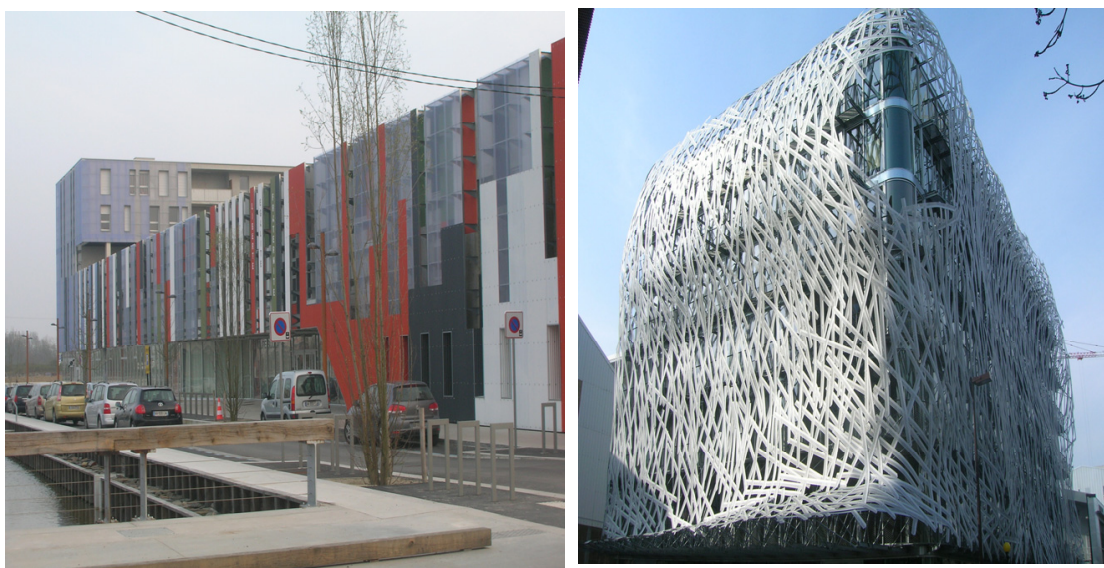

Figure 3: On the left the primary school with the workers' hostel in the background in La Bottière-Chénaie eco-districts; on the right the many building in Ile de Nantes (photos: Nathalie Long, 2011).

the optimisation of the space used for housing and infrastructures in order to preserve the space for plant life and water. Viewed from outside, the environmental impact of this district seems to be controlled.

On the Ile de Nantes, the diversity of buildings can also be observed, to the extent that the industrial port heritage has been preserved. Something of a working class district originally, the townhouses are now mixed with more modern structures and the sheds of the former shipyards have been converted into arts venues, restaurants or entertainment facilities. The functional mixity is also extremely present: the area features a school of architecture, housing, the regional council building, the Beaulieu shopping centre and the Machines de l'Ile for recreational activities. With the upgraded banks of the Loire, the creation of the Jardins de l'Ile de Nantes and conversion of sheds into recreational venues, the Ile is become a place for social interaction, walks and cycle rides. In this case, it is all about renewing in a sustainable manner the city within its boundaries, while preserving its industrial past.

Finally on the scale of buildings, the sustainability indicators can be identified on the basis of the examples of the two aforementioned districts. Without specifically returning to the form of buildings, we can note the diversity of materials and colours used and the façades of varying reliefs which catch the eye. These are decorative elements such as the Manny building or the Ile Rouge building on the Ile de Nantes or the veritable outer skin of insulation in wood for example, limiting the energy consumption of buildings (figure 3). A green roof was created on the media library. Residences come in several forms: they can be closed with inner courtyards laid out as private gardens and enabling separate access to the housing units with underground parking, or opening out to varying degrees, via a garden, onto the public space. 


\section{Conclusion}

The sustainable city is one of the key challenges of this century in terms of development of the territory and urban planning. Outside of conferences and international summits on the question, local actions give concrete form to these aspirations for sustainability and feed through at urban level to the emergence of new urban forms. This is why morphology has emerged as the obvious gateway for examining sustainability in the city. Whether by land use with the reintroduction of nature in the city or alternative systems of rain water management or by the form and organisation of constructions, the city is shedding its skin and sustainability criteria can be identified. This multi-scale analysis has made it possible to move from an overarching view of the territory to a more detailed vision via identification of elements which are specific to each of these scales. However, the multi-scale approach still raises certain problems, in particular the difficulty in identifying certain elements which can be grasped on several levels, such as the question of transport networks. Yet, application of these keys for understanding to the case of the Loire region has shown that these elements can be relevant on several territorial scales due to their spatial continuity. In fact, the Loire and its tributaries are natural assets at the level of the supra-urban territory but also at the level of the city and act on different criteria such as landscape diversity, the quality of life or alternative transport modes to the car. Nantes and more specifically the Nantes Metropolis offers a high profile for initiatives undertaken to ensure the sustainable development of their territory: on a large scale, projects are taking concrete form such as the building of eco-districts with an impact on the landscape which is often considerable (building construction materials, colours) but sustainability also remains identifiable on the supra-urban scale even if it is less visible (protecting and planting forests). The high visibility of these various projects helps to create a positive image which enhances appeal and drives urban growth. Consequently, the main challenge for administrators of this type of city is to reconcile this appeal with the imperatives of sustainability and, in particular, its social aspect. In fact, the gentrification of city centres and ecological inequalities are the undesirable results of certain urban innovations such as eco-districts [24]. Ultimately, although the sustainable city must be closely examined from the morphological perspective, it must also factor in its social, economic, cultural and political dimensions. The "sustainable city" object is therefore also fully grasped at the meeting point of these different notions.

\section{Acknowledgement}

This work is supported by the FEDER operational program.

\section{References}

[1] Alberti, M., The effects of urban patterns on ecosystem function. Int. Reg. Sci. Rev., 28(2), pp. 168-192, 2005. 
[2] Rodrigue, J-P., Transportation and Urban Form. http://people.hofstra. edu/geotrans/eng/ch6en/conc6en/ch6c1en.html

[3] Roseland, M., Dimensions of the eco-city. Cities, 14(4), pp. 197-202, 1997.

[4] Khare, A., Beckman, T. \& Crouse, N., Cities addressing climate change: Introducing a tripartite model for sustainable partnership. Sustainable Cities and Society, 1(4), pp. 227-235, 2011.

[5] Mega, V., Cities inventing the civilisation of sustainability: an odyssey in the urban archipelago of the European Union. Cities, 17(3), pp. 227-236, 2000.

[6] Emelianoff, C. \& Stegassy, R., Les pionniers de la ville durable - Récits d'acteurs, portraits de villes en Europe, Autrement, Paris, 2010.

[7] Clifton, K, Ewing, R, Knaap, G \& Song, Y., Quantitative analysis of urban form: a multidisciplinary review. Journal of Urbanism 1(1), pp. 17-45, 2008.

[8] Batty, M., The size, scale, and shape of cities. Science, 319, pp. 769-771, 2008.

[9] Jabareen, Y.R., Sustainable urban forms: their typologies, models, and concepts. J. Plan. Educ. Res. 26(1), pp. 38-52, 2006.

[10] Newman, P.W.G., Sustainability and cities: extending the metabolism model. Landscape and Urban Planning, 44, pp. 219-226, 1999.

[11] Roseland, M., Sustainable community development : integrating environmental, economic, and social objectives. Progress in Planning, 54 (2), pp. 73-132, 2000.

[12] Emelianoff, C., La notion de ville durable dans le contexte européen : quelques éléments de cadrage. Les Cahiers Français, 306, pp. 28-35, 2002.

[13] Grewal, S.S. \& Grewal, P.S., Can cities become self-reliant in food? Cities, 29(1), pp. 1-11, 2012.

[14] Zasada I.., Multifunctional peri-urban agriculture - A review of societal demands and the provision of goods and services by farming. Land use Policy, 28, pp. 639-648, 2011.

[15] Kuo, F.E. \& Sullivan, W.C., Environment and crime in the inner city. Does vegetation reduce crime ? Environment and Behavior, 33, pp. 343-367, 2011.

[16] Gidlöf-Gunnarsson, A. \& Öhrström, E., Noise and well-being in urban residential environments: The potential role of perceived availability to nearby green areas. Landscape and Urban Planning, 83, pp. 115-126, 2007.

[17] Arbury, J., From urban sprawl to compact city: an analysis of urban growth management in Auckland, Masters Thesis, University of Auckland, 2005.

[18] Dieleman, F. \& Wegener, M., Compact city and urban sprawl. Built Environ. 30(4), pp. 308-323, 2004.

[19] Yoshida H., Omae M., An approach for analysis of urban morphology: methods to derive morphological properties of city blocks by using an urban landscape model and their interpretations. Computers, Environment and Urban Systems, 29(2), pp. 223-247, 2005.

[20] Gauzin-Müller, D., Sustainable Architecture and urbanism, Basel, Birkhâuser, 2002. 
70 The Sustainable City VII, Vol. 1

[21] Nantes Métropole, 2010, L'agriculture à Nantes Métropole - un atout pour l'avenir, http://www.nantesmetropole.fr/medias/fichier/0668-themaagriculture-web_1278602555367.pdf

[22] Nantes Métropole, 2010, Evaluation environnementale du PDU, http://www.cmaintenant.eu/files/file/urbanisme_deplacements_consommati on_espace.pdf

[23] Nantes Métropole, 2012, Carte des producteurs / vendeurs de Nantes Métropole, http://www.nantesmetropole.fr/pratique/environnement/ decouvrir-l- agriculture-locale-30278.kjsp

[24] Martínez, J., The use of GIS and indicators to monitor intra-urban inequalities. A case study in Rosario, Argentina. Habitat International, 33(4), pp. 387-396, 2009. 